\section{TANGGUNG JAWAB PERUSAHAAN JASA TENAGA KERJA INDONESIA (PJTKI) TERHADAP PERLINDUNGAN TENAGA KERJA WANITA ${ }^{1}$}

Oleh : Herdy L. N Pihang ${ }^{2}$

\section{A B S T R A K}

Pasal 27 ayat (2) Undang-Undang Dasar 1945 menyebutkan bahwa tiap-tiap warga negara berhak atas pekerjaan dan penghidupan yang layak bagi kemanusiaan. Pembangunan ketenagakerjaan sebagai bagian dari pembangunan nasional berdasarkan Pancasila dan Undang-undang Dasar Negara Republik Indonesia Tahun 1945, dilaksanakan untuk pembangunan setiap warga Indonesia seutuhnya untuk meningkatkan harkat, martabat dan harga diri tenaga kerja serta mewujudkan masyarakat sejahtera, adil dan makmur. Berdasarkan Undang-Undang Nomor 13 Tahun 2003 Tentang Ketenagakerjaan merupakan salah satu solusi dalam perlindungan buruh maupun majikan tentang hak dan kewajiban masing-masing pihak. Dengan demikian, peraturan ini sangat berarti dalam mengatur hak dan kewajiban bagi para tenaga kerja maupun para pengusaha di dalam melaksanakan suatu mekanisme proses produksi. Penelitian ini bertujuan untuk mengetahui tentang Tanggung jawab Perusahaan Jasa Tenaga Kerja Indonesia (PJTKI) terhadap Tenaga Kerja Wanita serta Perlindungan dan Penegakkan Hukum yang dilakukan oleh Perusahaan Jasa Tenaga Kerja Indonesia (PJTKI) terhadap Tenaga Kerja Wanita. Metode penelitian yang digunakan dalam penelitian ini yakni penelitian hukum normatif dengan mengumpulkan peraturan perundang-undangan, dan literaturliteratur yang diperoleh sebagai bahan penunjang penyusunan karya tulis melalui studi kepustakaan. Hasil penelitian menunjukkan bagaimana tanggung jawab

\footnotetext{
${ }^{1}$ Artikel Skripsi

${ }^{2}$ NIM 090711348
}

perusahaan jasa tenaga kerja Indonesia (PJTKI) terhadap Tenaga Kerja Wanita, serta bentuk Perlindungan yang dapat dilakukan Perusahaan Jasa Tenaga Kerja Indonesia (PJTKI) terhadap Tenaga Kerja Wanita. Pertama, tanggung jawab perusahaan jasa tenaga kerja Indonesia terhadap TKW yakni keselamatan dan kesejahteraan tenaga kerja dari daerah asal sampai dengan kedatangan dari luar negeri, kepulangannya ke tempat asal dan keberangkatan kembali setelah cuti. Mengurus penyelesaian permasalahan yang timbul antara tenaga kerja dengan pengguna jasa berdasarkan perjanjian kerja yang sesuai dengan ketentuan peraturan perundang-undangan yang berlaku di negara setempat. Kedua, setiap calon tenaga kerja Indonesia mempunyai hak untuk memperoleh perlindungan sesuai dengan peraturan perundang-undangan. Perlindungan sebagaimana dimaksud di dalam undangundang Republik Indonesia nomor 39 tahun 2004 pada Pasal 77 ayat 1 di laksanakan mulai dari pra penempatan, masa penempatan, sampai purna penempatan. Perwakilan republik Indonesia memberikan perlindungan terhadap Tenaga Kerja dalam hal ini tenaga kerja wanita di luar negeri sesuai dengan peraturan perundangundangan.

Kata kunci: Tanggung jawab, perusahaan.

\section{PENDAHULUAN}

\section{A. LATAR BELAKANG PENELITIAN}

Pembangunan ketenagakerjaan sebagai bagian dari pembangunan nasional berdasarkan Pancasila dan Undang-undang Dasar Negara Republik Indonesia Tahun 1945, dilaksanakan untuk pembangunan setiap warga Indonesia seutuhnya untuk meningkatkan harkat, martabat dan harga diri tenaga kerja serta mewujudkan masyarakat sejahterah, adil dan makmur.

Pemerintah selaku penguasa negara berkepentingan agar roda perekonomian nasional dan pendistribusian penghasilan 
dapat berjalan dengan tertib dan lancar sehingga tidak membahayakan keamanan negara. Oleh karena itu, pemerintah berkewajiban agar peraturan perundangundangan dibidang ketenagakerjaan dapat berjalan dengan adil bagi para pihak sebagaimana mestinya. Untuk menjamin pelaksanaan perundang-undangan dibidang ketenagakerjaan dengan adil diperlukan campur tangan pemerintah melalui instansi/departemen yang khusus menangani masalah ketenagakerjaan yaitu Departemen Tenaga Kerja di tingkat pusat dan Dinas Tenaga Kerja ditingkat daerah. ${ }^{3}$

Bagi tenaga kerja wanita yang belum berkeluarga masalah yang timbul berbeda dengan yang sudah berkeluarga yang sifatnya lebih subyektif, meski secara umum dari kondisi objektif tidak ada perbedaan-perbedaan. Perhatian yang benar bagi pemerintah dan masyarakat terhadap tenaga kerja terlihat pada beberapa peraturan-peraturan yang memberikan kelonggaran-kelonggaran maupun larangan-larangan yang menyangkut pendirian seseorang wanita secara umum seperti cuti hamil, kerja pada malam hari dan sebagainya. Begitu juga yang dilakukan oleh perusahaan jasa tenaga kerja Indonesia terhadap calon tenaga kerja atau tenaga kerja yang akan diberangkatkan, baik yang akan di tempatkan di dalam negeri maupun diluar negeri, khususnya dalam hal ini tenaga kerja wanita. Setiap tenaga kerja yang sudah direkrut oleh Perusahaan Jasa Tenaga Kerja Indonesia (PJTKI) baik melalui kantor cabang Perusahaan Jasa Tenaga Kerja Indonesia (PJTKI) tersebut maupun kantor pusat, mempunyai tanggungjawab sepenuhnya terhadap tenaga kerja dari awal pengrekrutan sampai pada pemberangkatan dan kepulangan tenaga kerja tersebut. Tanggungjawab Perusahaan

3 Maimun, Hukum Ketenagakerjaan Suatu Pengantar, Pradnya Paramita, Jakarta, 2004, hal 34.
Jasa Tenaga Kerja Indonesia (PJTKI) setelah pengrekrutan tenaga kerja yaitu melakukan pelatihan, yang dilakukan selama pelatihan adalah mempelajari beberapa hal, misalnya bahasa yang dipakai, budaya dan tatakrama di negara dimana tenaga kerja akan ditempatkan, berikut yang dilakukan adalah uji keterampilan untuk menentukan kualifikasi keterampilan tenaga kerja, dan melakukan seleksi tenaga kerja yang akan diberangkatkan.

Hal-hal tersebut di atas merupakan tanggungjawab Perusahaan Jasa Tenaga Kerja Indonesia (PJTKI) terhadap tenaga kerja sebelum diberangkatkan, dan sesudah keberangkatan tenaga kerja ke luar negeri, bahkan konflik yang dialami oleh tenaga kerja sampai pada kembalinya tenaga kerja ke tanah air menjadi tanggungjawab dan perlindungan perusahaan jasa tenaga kerja Indonesia. Namun kenyataannya, tanggungjawab dan perlindungan terhadap tenaga kerja wanita belum menjamin kesejahteraan, dilihat dari beberapa kasus yang terjadi kepada tenaga kerja wanita yang bekerja di luar negeri yang mencerminkan kurangnya tanggungjawab dan perlindungan bagi mereka yang bekerja di luar negeri seperti beberapa kasus di bawah ini.

Penderitaan tenaga kerja wanita sebenarnya sudah dialami sejak lama bahkan penyiksaan tenaga kerja wanita terus berulang tanpa adanya penyelesaian hukum yang pasti. Masalah tenaga kerja saat ini terus berkembang semakin kompleks sehingga memerlukan penanganan yang lebih serius. Pada masa perkembangan tersebut pergeseran nilai dan tata kehidupan akan banyak terjadi. Pergeseran dimaksud tidak jarang melanggar peraturan perundang-undangan yang berlaku. Menghadapi pergeseran nilai dan tata kehidupan para pelaku industri dan perdagangan, pengawasan ketenagakerjaan dituntut untuk mampu mengambil langkah-langkah antisipatif 
serta mampu menampung segala perkembangan yang terjadi.

Berdasarkan Undang-Undang Nomor 13 Tahun 2003 Tentang Ketenagakerjaan merupakan salah satu solusi dalam perlindungan buruh maupun majikan tentang hak dan kewajiban masing-masing pihak. Dengan demikian, peraturan ini sangat berarti dalam mengatur hak dan kewajiban bagi para tenaga kerja maupun para pengusaha di dalam melaksanakan suatu mekanisme proses produksi.

Tidak kalah pentingnya adalah perlindungan tenaga kerja yang bertujuan agar bisa menjamin hak-hak dasar tenaga kerja dan menjamin kesempatan serta perlakuan tanpa diskriminasi. Begitu juga dengan penempatan tenaga kerja diluar negeri termasuk tenaga kerja wanita, yang di atur oleh Undang-undang Nomor 34 Tahun 2004 Tentang Perlindungan Tenaga Kerja di Luar Negeri. Menurut UndangUndang ini penempatan tenaga kerja Indonesia adalah kegiatan pelayanan untuk mempertemukan tenaga kerja sesuai bakat, minat dan kemampuannya dengan pemberi tenaga kerja diluar negeri yang meliputi keseluruhan proses perekrutan, pengurusan dokumen pendidikan dan pelatihan, penampungan, persiapan pemberangkatan sampai negara tujuan, dan pemulangan dari negara tujuan. Peranan wanita merupakan program koordinatif dengan instansi lain dibawa kordinasi Menteri Negara Peningkatan Peranan Wanita. Dilihat dari segi ketenagakerjaan program ini juga ditujukan untuk meningkatkan peran serta wanita dalam kegiatan produktif, sehingga dapat membantu meningkatkan kesejahteraan keluarganya. ${ }^{4}$ Pasal 31 Undang-undang Nomor 13 Tahun 2003 tantang ketenagakerjaan menyatakan bahwa prinsip penempatan tenaga kerja bahwa setiap tenaga kerja mempunyai hak dan

\footnotetext{
${ }^{4}$ Sendjun H. Manulang, Op. cit hal 30.
}

kesempatan yang sama untuk memilih, mendapatkan atau pindah pekerjaan dan memperoleh penghasilan yang layak di dalam atau diluar negeri. Jadi menurut ketentuan ini jelas tidak boleh ada perlakuan diskriminasi dalam bentuk apapun. $^{5}$

\section{B. RUMUSAN MASALAH}

1. Bagaimana Tanggung Jawab Perusahaan Jasa Tenaga Kerja Indonesia (PJTKI) terhadap Tenaga Kerja Wanita.

2. Bagaimana bentuk Perlindungan yang dapat dilakukan Perusahaan Jasa Tenaga Kerja Indonesia (PJTKI) terhadap Tenaga Kerja Wanita.

\section{METODE PENELITIAN}

Dalam penyusunan karya tulis ini penulis menggunakan penelitian hukum normatif dengan mengumpulkan peraturan perundang-undangan, dan literaturliteratur yang diperoleh sebagai bahan penunjang penyusunan karya tulis melalui studi kepustakaan.

Bahan-bahan hukum yang telah dikumpulkan tentunya berkaitan dengan tanggung jawab perusahaan jasa tenaga kerja Indonesia (PJTKI) serta buku-buku tentang tenaga kerja. Peraturan perundang-undangan sebagai bahan hukum primer dan literatur-literatur sebagai bahan hukum sekunder kemudian dianalisa secara kualitatif.

\section{PEMBAHASAN}

1. Tanggung Jawab Perusahaan Jasa Tenaga Kerja (PJTKI) terhadap Tenaga Kerja Wanita

Penyediaan kesempatan kerja baik dalam negeri maupun luar negeri, tidak menutup kemungkinan bahwa wanita mempunyai peran aktif dalam meningkatkan kesejahteraan keluarganya

5 Abdul Khakim, Dasar-dasar Hukum Ketenagakerjaan Indonesia, Citra Aditya Bakti, Bandung, 2009, hal 21. 
untuk itu begitu banyak wanita yang menjadi tenaga kerja baik diluar negeri maupun didalam negeri.

Dimaksud dengan penempatan tenaga kerja dalam Pasal 1 Peraturan Menteri Tenaga Kerja Nomor : PER-02/MEN/1994 adalah kegiatan pengerahan tenaga kerja yang dilakukan dalam rangka proses Antar Kerja untuk mempertemukan persediaan dan dan permintaan tenaga kerja baik dalam maupun luar negeri (huruf (a). Sedangkan Antar Kerja adalah suatu mekanisme pelayanan kepada pencari kerja untuk memperoleh pekerjaan sesuai dengan bakat, minat dan kemampuannya baik untuk sementara waktu maupun tetap, serta pelayanan kepada pemberi kerja untuk sementara waktu maupun tetap, serta pelayanan kepada pemberi kerja untuk memperoleh tenaga kerja yang sesuai kebutuhannya (huruf b). Sedangkan yang dimaksud dengan tenaga kerja dalam Peraturan Menteri Tenaga Kerja adalah setiap orang yang mampu melakukan pekerjaan baik di dalam maupun di luar hubungan kerja guna menghasilkan jasa atau barang untuk memenuhi kebutuhan masyarakat (huruf c). Sesuai Pasal 2 untuk melaksanakan penempatan tenaga Kerja di dalam dan di luar negeri harus menaati ketentuan yang ditetapkan Menteri Tenaga Kerja. ${ }^{6}$

Pelaksanaan penempatan tenaga kerja (Pasal 3) dilaksanakan secara tertip, efisien dan efektif. Tujuannya adalah untuk mencapai peningkatan kesejahteraan tenaga kerja, pemasukan devisa, perluasan lapangan kerja, dan keberhasilan usaha jasa penempatan tenaga kerja. Untuk itu harus diperhatikan harkat dan martabat bangsa dan negara melalui pendayagunaan penempatan pasar kerja di dalam dan di luar negeri. ${ }^{7}$

\footnotetext{
${ }^{6}$ Darwan Prinst, Hukum Ketenagakerjaan Indonesia, Citra Aditya Bakti, Bandung, 2000, hal 83.

${ }^{7}$ Ibit, hal 84
}

Perusahaan jasa tenaga kerja Indonesia (PJTKI), adalah badan usaha yang berbentuk perseroan terbatas (PT) yang memiliki Surat Izin Usaha (SIU-PJTKI) untuk melaksanakan kegiatan jasa penempatan tenaga kerja di dalam dan keluar negeri. ${ }^{8}$ Lembaga pelaksanaan penempatan tenaga kerja melaksanakan tugas kegiatan penempatan tenaga kerja sesuai dengan proses Antar Kerja, baik di dalam dan atau di luar negeri.

Adapun hak-hak dari lembaga pelaksanaan penempatan tenaga kerja sesuai dengan status dan persyaratan kelembagaan adalah sebagai berikut :

1) Menempatkan tenaga kerja di dalam dan ke luar negeri.

2) Menyediakan tenaga kerja yang diperlukan Pengguna Jasa baik di dalam maupun luar negeri.

3) Memperoleh informasi pasar kerja dari dalam dan ke luar negeri.

4) Memperoleh bimbingan dan pembinaan dari Departemen Tenaga Kerja

5) Mendapat biaya jasa penempatan dari pengguna jasa di dalam maupun luar negeri.

6) Mendapat biaya jasa penempatan dari tenaga kerja sesuai dengan ketentuan yang berlaku.

7) Mengelolah bank data tenaga kerja terampil atau berpengalaman.

Adapun kewajban pelaksana penempatan tenaga kerja adalah sebagai berikut :

1) Melaksanakan penempatan tenaga kerja.

2) Memenuhi persyaratan yang ditetapkan sesuai dengan ruang lingkup kegiatan.

3) Melaksanakan dan mematuhi petunjuk dari Departemen Tenaga Kerja.

4) Menyiapkan Tenaga Kerja Indonesia yang berkualitas dalam segi mental,

${ }^{8}$ Ibit, hal 85 
fisik, keterampilan teknis dan kemampuan berkomunikasi.

5) Melaksanakan promosi dan pemasaran Jasa TKI.

6) Melaporkan setiap penempatan, pemberangkatan dan pemulangan

TKI kepada Departemen Tenaga Kerja secara berkala dan insidental untuk hal yang khusus.

7) Memberikan perlindungan kepada tenaga kerja mulai dari pra sampai dengan purna penempatan, termasuk pengamanan pelaksanaan perjanjian

kerja yang mengikat Pengguna Jasa TKI.

8) Membuat laporan usaha dalam bentuk laporan semesteran dan laporan tahunan harus diaudit oleh Akuntan Publik. ${ }^{9}$

PJTKI dapat melakukan kegiatan penempatan tenaga kerja untuk suatu paket kontrak pekerjaan penyediaan dan pengelolaan tenaga kerja. Untuk itu PJTKI harus mendapat persetujuan tertulis dari Direktur Jenderal Pembinaan Penempatan Tenaga kerja atas nama Menteri. Untuk mendapatkan persetujuan itu PJTKI harus mengajukan permohonan tertulis dengan meterai cukup. Permohonan ditujukan kepada Direktur Jenderal Penempatan Tenaga Kerja, dengan melampiri:

1) Perjanjian antara PJTKI dengan Badan Hukum Pemberi Kerja yang memuat pemberian tugas, hak dan kewajiban untuk melaksanakan penyediaan dan pengelolaan tenaga kerja yang diperlukan.

2) Perjanjian kerja antara PJTKI dengan tenaga kerja yang akan ditempatkan, yang memuat syarat dan kondisi kerja serta hak dan kewajiban masingmasing pihak.

3) Surat pernyataan kesediaan untuk bertanggung jawab terhadap penyelesaian setiap permasalahan yang terjadi dalam penempatan tenaga kerja sesuai dengan ketentuan peraturan perundang-undangan yang berlaku. $^{10}$

Penempatan tenaga kerja yang telah mendapat persetujuan harus memenuhi ketentuan yaitu:

1) Laporan pemberangkatan dan kepulangan tenaga kerja.

2) Program pengiriman remittan dan tabungan bagi tenaga kerja yang bekerja diluar negeri.

3) tanggung jawab perlindungan tenaga kerja.

PJTKI baik sendiri atau berkelompok dapat menunjuk perwakilan Luar Negeri untuk mengurus kepentingannya di negara penempatan tenaga kerja. Malahan bila dipandang perlu Perwakilan Luar negeri harus memiliki karyawan yang dapat berbahasa Indonesia. Perwakilan luar negeri yang memenuhi persyaratan tersebut harus dilaporkan kepada Perwakilan RI setempat.

Adapun yang menjadi tugas dan tanggung jawab dari perwakilan luar negeri yaitu :

1) Melakukan pemasaran Jasa Tenaga Kerja Indonesia.

2) Mencari lowongan pekerjaan.

3) Menandatangani dokumen yang berkaitan dengan penempatan Tenaga Kerja Indonesia untuk dan atas nama PJTKI.

4) Memantau pelaksanaan isi perjanjian kerja.

5) Menyelesaikan setiap permasalahan yang timbul antara Tenaga Kerja Indonesia dengan pengguna jasa.

6) Mengurus perpanjangan kontrak kerja, cuti dan pemulangan Tenaga Kerja Indonesia. ${ }^{11}$

\footnotetext{
${ }^{10} \mathrm{Ibit}$, hal 92

${ }^{11}$ lbit, hal 93
} 
Lembaga pelaksanaan penempatan tenaga kerja, sebelum melaksanakan penempatan tenaga kerja di luar negeri diharuskan memenuhi kewajiban yang berkaitan dengan perlindungan tenaga kerja diantaranya :

a) Persyaratan tenaga kerja.

b) Seleksi terhadap kaulitas calon pengguna jasa tenaga kerja.

c) Kejelasan dan kepastian perlindungan hukum bagi tenaga kerja dalam Jamsostek atau sistem jaminan kesejahteraan TKI serta sistem asuransi lainnya di negara penempatan tenaga kerja. $^{12}$

Perusahaan Jasa Tenaga Kerja Indonesia (PJTKI) yang memiliki surat izin usaha PJTKI melakukan pengretrutan para calon tenaga kerja, pengretrutan dilakukan oleh cabangcabang Perusahaan Jasa Tenaga Kerja Indonesia (PJTKI) baik dari data-data yang dibutuhkan sebagai persyaratan menjadi tenaga kerja semua di lengkapi oleh setiap calon tenaga kerja yang mendaftarkan diri ke cabang-cabang perusahaan jasa tenaga kerja Indonesia (PJTKI), setelah itu datadata yang sudah ada telah diverifikasi dikirim ke kantor pusat PJTKI dan selanjutnya melakukan tindakan berikut yang meliputi penyiapan kualitas tenaga kerja sampai pada keberangkatan. Karena adanya program penempatan tenaga kerja di dalam maupun ke luar negeri, melibatkan banyak lembaga-lembaga Depnaker, PJTKI, BP3TKI, Departemen Kesehatan, Imigrasi dan kepolisian. Sesuai dengan peran, fungsi dan tanggung jawab terhadap tenaga kerja sebelum keberangkatan perusahaan jasa tenaga kerja Indonesia (PJTKI) melakukan pelatihan, uji keterampilan yang menjadi bekal bagi tenaga kerja indonesia yang akan

\footnotetext{
12 Lalu Husni, Pengantar Hukum Ketenagakerjaan Indonesia cetakan ke 3, PT Raja Grafindo Persada, Jakarta, 2003, hal 70
}

diberangkatkan ke negara dimana tenaga kerja tersebut di tempatkan. ${ }^{13}$

\section{Bentuk-bentuk Perlindungan Perusahaan Jasa Tenaga Kerja Indonesia (PJTKI) terhadap Tenaga Kerja Wanita}

Perlindungan tenaga kerja sangat mendapat perhatian dalam hukum ketenagakerjaan. Beberapa pasal dalam Undang-undang Nomor 13 tahun 2003 tentang ketenagakerjaan diantaranya mengatur hal itu.

1. Salah satu tujuan pembangunan ketenagakerjaan adalah memberikan perlindungan kepada tenaga kerja dalam mewujudkan kesejahteraan (Pasal 4 hufuf c).

2. Setiap tenaga kerja memiliki kesempatan yang sama tanpa diskriminasi untuk memperoleh pekerjaan (Pasal 5)

3. Setiap pekerja berhak memperoleh perlakuan yang sama tanpa diskriminasi dari pengusaha (Pasal 6).

4. Setiap tenaga kerja berhak untuk memperoleh dan/atau meningkatkan dan/atau mengembangkan kopetensi kerja sesuai dengan bakat minat, dan kemampuannya melalui pelatihan kerja (Pasal 11)

5. Setiap pekerja memiliki kesempatan yang sama untuk mengikuti pelatihan kerja sesuai dengan bidang tugasnya (Pasal 12 ayat (3)).

6. Setiap tenaga kerja mempunyai hak dan kesempatan yang sama untuk memilih, mendapatkan atau pindah pekerjaan dan memperoleh penghasilan yang layak di dalam atau di luar negeri (Pasal 31).

7. Setiap pekerja berhak memperoleh perlindungan atas keselamatan dan kesehatan kerja, moral dan kesusilaan, dan perlakuan yang sesuai dengan

\footnotetext{
${ }^{13}$ Wawancara, dengan lbu Yeni pengurus di PJTKI, PT. Elsa Putra Indah, tanggal 10 mei 2013
} 
harkat dan martabat manusia serta nilainilai agama (Pasal 86 (1)).

8. Setiap pekerja berhak memperoleh penghasilan yang memenuhi penghidupan yang layak bagi kemanusiaan (Pasal 88 ayat (1)).

9. Setiap pekerja dan keluarganya berhak untuk memperoleh jaminan sosial tenaga kerja (Pasal 99 ayat (1)).

Pasal 5 secara yuridis memberikan perlindungan bahwa setiap tenaga kerja berhak mempunyai kesempatan yang sama untuk memperoleh pekerjaan dan penghidupan yang layak tanpa membedakan jenis kelamin, suku, ras, agama, dan aliran politik, sesuai dengan minat dan kemampuan tenaga kerja yang bersangkutan. Pasal 6 mewajibkan pengusaha untuk memberikan hak dan kewajiban kepada pekerja tanpa embedakan jenis kelamin, suku, ras, agama, warna kulit, dan aliran politik. ${ }^{14}$

Setiap calon tenaga kerja Indonesia Mempunyai hak untuk memperoleh perlindungan sesuai dengan peraturan Perundang-undangan. Perlindungan sebagaimana dimaksud di dalam undangundang Republik Indonesia nomor 39 tahun 2004 pada Pasal 77 ayat 1 dilaksanakan mulai dari pra penempatan, masa penempatan, sampai purna penempatan. Perwakilan republik Indonesia memberikan perlindungan terhadap Tenaga Kerja dalam hal ini tenaga kerja wanita di luar negeri sesuai dengan peraturan perundangundangan serta hukum kebiasaan internasional.

Setiap Tenaga Kerja Indonesia dalam hal ini tenaga kerja wanita yang ditempatkan ke luar negeri oleh PJTKI sepenuhnya akan dlindungi oleh PJTKI. PJTKI bekerja sama dengan pemerintah dalam hal perlindungan terhadap Tenaga Kerja Indonesia dari pra penempatan sampai pada purna penempatan. Seperti yang telah kita lihat

\footnotetext{
${ }^{14}$ Abdul Khakim, Op. cit, hal 106
}

pada penjelasan diatas, perlindungan dilakukan sesuai dengan aturan dan ketentuan yang berlaku. Salah satu bentuk perlindungan PJTKI terhadap TKI pada saat pra penempatan, misalkan calon tenaga kerja yang telah menandatangani perjanjian kerja lalu mengalami kecelakaan sebelum berangkat, dan sampai pada kembalinya, TKI harus mendapat perlindungan karena adakalanya terjadi pemerasan-pemerasan yang dialami oleh TKI setelah kembali ke negara asal. Dilihat dari kenyataan yang ada, begitu banyak masalah yang di alami oleh TKI yang kerja ke luar negeri dan seolah-olah perlindungan dari PJTKI tidak efektif, misalnya ketika TKI mengalami masalah di luar negeri proses memulangkan TKI yang bermasalah tersebut kelihatannya lambat, ini disebabkan pada saat pengretrutan calon tenaga kerja oleh kantor cabang PJTKI, data atau dokumen dari setiap calon tenaga kerja yang telah di seleksi oleh kantor cabang PJTKI tersebut tidak di simpan pada kantor pusat PJTKI, dan saat terjadi masalah, mengalami kesulitan dalam memulangkan TKI tersebut. Jadi ini juga menjadi perhatian bagi PJTKI dalam hal pendataan dan dokumen-dokumen dari setiap calon TKI harus benar-benar terdaftar di kantor Pusat PJTKI dari awal pengretrutan, ini juga bentuk perlindungan terhadap TKI yang bekerja di luar negeri.

\section{PENUTUP}

\section{A. Kesimpulan}

1. Perusahaan jasa tenaga kerja Indonesia (PJTKI) yang melakukan pengiriman tenaga kerja kerja ke luar negeri diwajibkan memiliki SIUP-PJTKI yang diterbitkan oleh Direktur Jenderal Pembinaan Penempatan Tenaga Kerja atas nama Menteri. Koordinasi antara Tenaga Kerja Indonesia sendiri dengan Perusahaan Jasa Tenaga Kerja Indonesia, mitra usaha atau perwakilan luar negeri dan pemerintah untuk dapat mengirim 
tenaga kerja indonesia dalam hal ini tenaga kerja wanita. Sebelum penempatan di luar negeri Tenaga Kerja Indonesia diberi pendidikan dan keterampilan kemudian diseleksi yang akan dikirim ke luar negeri. Tenaga Kerja Indonesia yang bekerja di luar negeri harus memiliki pendidikan dan keterampilan kerja sesuai dengan bidangnya. Tenaga kerja yang belum memiliki keterampilan harus mengikuti pelatihan pada Balai Latihan Kerja (BLK) atau Balai Latihan Kerja Luar Negeri

(BLKN) yang dikelola oleh Perusahaan Jasa Tenaga Kerja Indonesia.

2. Pengiriman Tenaga Kerja Indonesia dan penempatannya di negara pengguna jasa Tenaga Kerja Indonesia, tidak lepas dari perlindungan Perusahaan Jasa Tenaga Kerja Indonesia yang bekerja sama dengan pemeritah, baik pelindungan pra penempatan yang di dalamnya mempersiapkan tenaga kerja untuk menerima penyiapan kualitas dan mempersiapkan dokumen-dokumen yang harus dipersiapkan tenaga kerja Indonesia sebelum penempatan, dan sampai pada penempatan, dalam hal ini mitra usaha yang mempunyai hubungan dengan Perusahaan Jasa Tenaga Kerja Indonesia yang mengirimkan tenaga kerja tersebut dalam hal ini tenaga kerja wanita, bersama-sama dengan perwakilan luar negeri membantu tenaga kerja Indonesia selama di luar negeri dalam rangka perlindungan terhadap tenaga kerja Indonesia sampai pada kembalinya tenaga kerja ke negara asal masih tetap dalam tanggung jawab serta perlindungan oleh Perusahaan Jasa Tenaga Kerja. perlindungan Tenaga Kerja Indonesia dilaksanakan secara terpadu dan lintas sektoral antara instansi pemerintah baik pusat maupun daerah dan partisipasi masyarakat dalam suatu sistem hukum yang mampu melindungi Tenaga Kerja Indonesia di luar negeri. Di dalam Undang-undang Nomor 39 tahun 2004 dapat digunakan sebagai substansi perbincangan hukum ketenagakerjaan khususnya yang terkait dengan penempatan dan perlindungan Tenaga Kerja Indonesia di luar negeri.

\section{B. Saran}

1. Perlunya satu atap dalam mengelola para TKI yaitu PJTKI setempat bekerjasama dengan Depnakertrans dan instansi terkait untuk menyaring dan menyeleksi para TKI yang akan berangkat ke Luar Negeri.

2. Perlunya pengawasan terhadap Perusahaan Jasa Tenaga Kerja Indonesia dalam memberikan materi pembekalan atau penyiapan kualitas tenaga kerja Indonesia dalam hal ini tenaga kerja wanita agar pembekalan benar-benar diberikan sesuai dengan kurikulum yang harus di bekali kepada setiap Tenaga Kerja Indonesia.

3. Perlunya dibekali pendidikan/pemahaman para TKI yang akan berangkat ke Luar Negeri tentang bahasa, budaya, etika negara penerima TKI di Luar Negeri agar tidak terjadi kekerasan oleh majikan di Luar Negeri.

4. Sebelum diberangkatkan diharapkan agar Perusahaan Jasa Tenaga Kerja benar-benar melakukan seleksi bagi Tenaga Kerja Indonesia yang akan di berangkatkan supaya pada saat pemberangkatan, tenaga Kerja Indonesia dalam hal ini tenaga kerja wanita yang akan ditempatkan sudah siap untuk bekerja dan ditempatkan di sektor mana saja sesuai dengan profesi dan kualitas yang dimiliki.

5. Kiranya perlu di tingkatkan komunkasi antara Perusahaan Jasa Tenaga Kerja Indonesia dengan tenaga kerja dalam hal ini tenaga kerja wanita yang di kirimnya maupun dengan mitra usaha yang di luar negeri yang memantau 
keberadaan Tenaga Kerja Indonesia agar dapat mengetahui secara jelas perkembangan dari tenaga kerja tersebut, ini termasuk dalam tanggung jawab serta perlindungan yang efektif dari Perusahaan Jasa Tenaga Kerja Indonesia terhadap Tenaga Kerja Indonesia yang dikirim ke luar negeri.

\section{DAFTAR PUSTAKA}

Abdul, et.al, Hukum Bisnis untuk Perusahaan, Kencana, Jakarta, 2008.

Husni Lalu (1), Pengatar Hukum Ketenagakerjaan Indonesia cetakan ke 2, Jakarta, PT Raja Grafindo Persada, 2001.

(2), Pengantar Hukum

Ketenagakerjaan Indonesia cetakan ke 3, PT Raja Grafindo Persada, Jakarta, 2003. (3), pengantar hukum ketenagakerjaan Indonesia Edisi Revisi, Jakarta PT Grafindo Persada, 2009.

Hadhikusuma R. Surantya R.T. dan Sumantoro, Pengertian Pokok Hukum Perusahaan, ajawali, Jakarta, 1992.

Kansil, C.S.T dan Kansil S.T, Christine S.T (1), Hukum Perusahaan Indonesia, Pradnya Paramita, Jakarta, 2001.

(2), Pokok-pokok Pengetahuan Hukum Dagang Indonesia, Sinar Grafik, Jakarta, 2002.

Khakim Abdul, Dasar-dasar Hukum Ketenagakerjaan Indonesia, Citra Aditya Bakti, Bandung, 2009.

Manulung H. Sendjun, Pokok-pokok Hukum Ketenagakerjaan di Indonesia, Rineka Cipta, Jakarta, 1987.

Maimun, Hukum Ketenagakerjaan Suatu Pengantar, Pradnya Paramita, Jakarta, 2004.

Prinst Darwan, Hukum Ketenagakerjaan Indonesia, Citra Aditya Bakti, Bandung, 2000.

Pitoyo Whimbo, Paduan Praktis Hukum Ketenagakerjaan, Jakarta, Transmedia Pustaka, 2010.
Supramono Gatot, Kedudukan Perusahaan Sebagai Subjek dalam Gugatan Perdata di Pengadilan, Rineka Cipta, Jakarta, 2007.

Sutedi Adrian, Hukum Perburuhan, Sinar Grafik, Jakarta, 2009.

\section{Sumber Undang-Undang}

Undang-Undang Dasar Republik Indonesia 1945

Undang-Undang Nomor 13 Tahun 2003 Tentang Ketenagakerjaan

Undang-Undang Nomor 34 Tahun 2004 Tentang Penempatan dan Perlindungan Tenaga Kerja Indonesia di Luar Negeri

\section{Sumber-Sumber Lain}

http://nasional.news.viva.co.id/news/read/ 322229-tkw-asal-Cianjur-diperkosa-

Polisi-di-Arab.kekerasan dan pemerkosaan yang di alami oleh TKI asal Cianjur Jawa Barat. 14 maret 2013.

http://news.liputan6.com/read/342925/elis -pulang-dari-arab-membawa-duka TKI asal desa hegarmana, kabupaten cianjur gaji tidak dibayarkan oleh majikan dan kerap kali mengalami kekerasan. 14 maret 2013.

Wawancara dengan Ibu Yeni pengurus di PJTKI, PT. Elsa Putra Indah, 10 mei 2013. 